\title{
UMA PUBLICIDADE AMAZÔNICA COMO SIGNO DO CONSUMO CONTEMPORÂNEO
}

\author{
An amazon publicITY as a sign of contemporary \\ consumption
Una publiCIDAD amazónica como signo de consumo contemporáneo

\author{
Luiz LZ Cezar Silva dos Santos \\ Universidade Federal do Pará, Belém, Brasil. \\ Doutor em História pela Pontifícia Universidade Católica de São Paulo (PUC-SP). Mestre em Estudos \\ Literários pela Universidade Federal de Minas Gerais (UFMG) \\ E-mail: Izcezar@ufpa.br
}

RESUMO Este texto tem como argumento decodificar o conceito de publiCIDADE como um instrumento de análise de marca e expressão do consumo, bem como um possível caminho para pensar a cidade contemporânea em seus aspectos sígnicos. Tendo por base uma cidade amazônica - Belém do Pará -, buscaremos entender tanto o que é uma cidade e como podemos compreendê-la como um espaço urbano quanto suas relações midiáticas e associações como signos do consumo contemporâneo. Para nossa reflexão, utilizaremos estudos sobre cidade, consumo, marca, marca Amazônia e publiCIDADE.

PALAVRAS-CHAVE publicIDADE, Marca, Consumo, Amazônia, Signo.

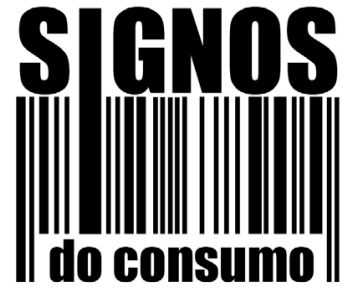

artigo

\begin{abstract}
This text aims to decode the concept of publiCITY as an instrument of analysis of brand and consumption expression and as a possible way of thinking the contemporary city in its aspects of signs. Based on an Amazon city - Belém do Pará -, we will try to understand both what is a city and how can we understand it as an urban space regarding its mediatic relations and associations as signs of contemporary consumption. For our reflection, we will use studies about city, consumption, brand, Amazon brand and publiCITY.
\end{abstract}

KEYWORDS PubliCITY, Brand, Consumption, Amazon, Sign.

RESUMEN Este texto tiene por objetivo decodificar el concepto de publiCIDAD como instrumento de análisis de la marca y expresión de consumo que converge en la ciudad, así como pensar la ciudad contemporánea en sus aspectos sígnicos. A partir de la ciudad amazónica de Belém do Pará (Brasil), se pretende entender qué es una ciudad y cómo podemos interpretarla mientras espacio urbano respecto a sus relaciones con los medios y asociaciones como signos de consumo contemporáneo. Para esta reflexión, se utilizarán los estudios sobre la ciudad, la marca, la marca Amazonía y la publiCIDAD.

PALABRAS-CLAVE PubliCIDAD, Marca, Consumo, Amazonas, Signo.

\section{OS PORTÕES DA PUBLICIDADE}

Na Antiguidade, a primeira coisa com a qual os viajantes se deparavam ao chegarem à porta de entrada de qualquer cidade fortificada eram os portões, símbolos indeléveis da capacidade de defesa e da grandeza da cidade conforme seu tamanho e materialidade. 
A cidade da Idade Média é um espaço fechado. A muralha a define. Penetra-se nela por portas e nela se caminha por ruas infernais que, felizmente, desembocam em praças paradisíacas. Ela é guarnecida de torres, torres das igrejas, das casas dos ricos e da muralha que a cerca. Lugar de cobiça, a cidade aspira à segurança. (LE GOFF, 1998, p. 71)

Todavia, para Le Goff (1998), na modernidade, bem como na contemporaneidade:

A cidade contemporânea, apesar de grandes transformações, está mais próxima da cidade medieval do que esta última da cidade antiga. A cidade da Idade Média é uma sociedade abundante, concentrada em um pequeno espaço, um lugar de produção e de trocas em que se mesclam o artesanato e o comércio de alimentos por uma economia monetária. (LE GOFF, 1998, p. 25)

Assim, como porta de entrada da nossa pesquisa, apresentamos a ideia de publicIDADE, termo que faz referência ao que é "público" e à "cidade". Para uma leitura conceitual do termo publicIDADE, ou seja, a separação escrita de "publi" em caixa baixa e de "CIDADE" em caixa alta, queremos demonstrar a importância correlacional entre as grafias "público" e "cidade" e a sua relação comunicacional com o termo "publicidade" como forma de analisar todas as representações possíveis construídas pelo propagar da comunicação sobre a(s) publiCIDADE(S) existentes mundo afora, uma análise das mais diversas possibilidades de pesquisa da(s) sociedade(s) que a(s) produz(em) e da(s) sociedades(s) e do(s) público(s) que a(s) consome(m).

Ao problematizarmos o termo "público", encontramos caminhos como: relativo ou pertencente a um povo, a uma coletividade; relativo ou pertencente ao governo de um país, estado, cidade etc.; pertencente a todos, comum por oposição ao privado. Como podemos observar, o conceito de público se subdivide e é composto de diversos significados e expressões - governo, país, estado, cidade - e os termos comunicação e opinião também entram nessa lista. Historicamente, a função da opinião pública é um atributo de quem desperta os relacionamentos com o público, ou seja, os profissionais das relações públicas. Nesse sentido, segundo Habermas (2003, p. 41), “o que é submetido ao julgamento do público ganha "publicidade””.

Só que os reflexivos contemporâneos da esfera pública evoluída tinham de observar como esse véu rasgou; o público se amplia, primeiro informalmente, através da difusão da imprensa e da propaganda; junto com a sua exclusividade social, perde também o contexto através dos institutos da sociabilidade e de um nível relativamente elevado de formação intelectual. (HABERMAS, 2003, p. 158)

Se para Habermas (2003) é a partir de um rígido código de comportamento nobre que percebemos que a evolução da representatividade pública está ligada aos atributos da pessoa - insígnias, como emblemas e armas, hábitos, de vestimenta ou o penteado, gestos, como a forma de saudar e comportamentos, e retórica, seja a forma de falar ou o discurso utilizado em geral -, por que não pensar hoje essas representações comportamentais que se fazem presentes na publicização de produtos e serviços e nas marcas evocadas diariamente pelo arauto das mensagens publicitárias nos espaços urbanos e rurais? Nesse debate, 
incluímos a cidade como um "produto", como uma publiCIDADE que deve ser divulgada, propagada e anunciada como o "lugar" que o público alvo da divulgação deve conhecer e, na maioria das vezes, comprar, principalmente como um lugar turístico.

Simplificando o entendimento do que é cidade, podemos compreendêla como o espaço urbano de um município delimitado por um perímetro. Ademais, para ser considerada uma cidade, o espaço precisa ter um número mínimo de habitantes e uma infraestrutura que atenda minimamente às condições da população. Portanto, para o nosso estudo, a ideia de publicIDADE também se refere ao estudo das cidades como fenômenos históricos, espaços urbanos e rurais, pontos turísticos, signos de consumo e ambiências para os processos midiáticos.

O consumo é um sistema simbólico que articula coisas e seres humanos e, como tal, uma forma privilegiada de ler o mundo que nos cerca. Através dele a cultura expressa princípios, estilos de vida, ideias, categorias, identidades sociais e projetos coletivos. (ROCHA, 2006, p. 86)

Para Rocha (2006), o consumo é um dos grandes inventores das atuais classificações sociais que regulam as nossas visões de mundo. Daí estudarmos as publicIDADES como produtoras de sentidos e de imagens que circulam pelos e nos espaços urbanos como lócus de estudo dos processos socioculturais e políticos e suas representações de consumo, midiáticas e interpretativas da e pela comunicação.

Tomemos como exemplo de consumo de uma publiCIDADE a cidade de Belém, capital do estado do Pará, geograficamente situada na região Norte do Brasil, na região amazônica, e banhada pelas águas dos rios Guamá e Guajará. Historicamente e publicitariamente, a entrada principal - os "portões" - da cidade são as águas dos rios e os furos que banham Belém (Figura 1).

Belém foi fundada em 12 de janeiro de 1616 pelo capitãomor Francisco Caldeira Castelo Branco, encarregado pela coroa portuguesa de conquistar, ocupar, explorar e proteger a foz do rio Amazonas contra os corsários holandeses e ingleses. Numa península habitada pelos índios Tupinambás, estrategicamente situada numa margem direita da foz do rio Guamá, onde este rio deságua na Baia do Guajará, foi erguido o Forte do Presépio, marco inicial da cidade. (BELÉMTUR, 2019, p. 10)

Para Barbosa e Campbell: “o consumo é ambíguo porque por vezes é entendido como uso e manipulação e/ou como experiência; em outras, como compra, em outras ainda como exaustão, esgotamento e realização" (2006, p. 21). Ainda segundo os autores:

Os mesmos objetos, bens e serviço que matam nossa fome, nos abrigam do tempo, saciam nossa sede, entre outras "necessidades" físicas e biológicas, são consumidos no sentido de "esgotamento", e utilizados também para medir nossas relações sociais, nos conferir status, "construir" identidades e estabelecer fronteiras entre grupos e pessoas”. (BARBOSA; CAMPBELL, 2006, p. 22)

Nesse sentido, podemos utilizar a argumentação de Barbosa e Campbell (2006) como forma de elucidar ainda mais o conceito de publicIDADE proposto neste estudo. 
No Dicionário do desenvolvimento ${ }^{1}$ encontramos a definição clássica:

Uma cidade é uma área urbanizada, que se diferencia de vilas e outros espaços urbanos através de vários critérios: população, infraestrutura, organização, serviços, entre outros. Uma cidade caracteriza-se por um estilo de vida particular dos seus habitantes, pela urbanização e pela concentração de atividades económicas. Cada país define os seus próprios critérios para a definição de cidade.

(CIDADES, 2020)

Desse modo, pretendemos, ao estudar a publicidade, pensar as formas como tais fenômenos delimitam o(s) espaço(s) real(is) e imaginário(s) e condicionam a geração de sentidos nas cidades. O estudo utilizará as atividades da publicidade e da propaganda como referências midiáticas de investigação dos diversos e múltiplos fenômenos de consumo e comunicação na contemporaneidade e a relação de tais fenômenos com as marcas nas diversas narrativas culturais, históricas e sociais que instauram representações do ser e do estar.

A pesquisa também se propõe a refletir sobre as relações entre a publicidade, a História e o viver urbano nas publicIDADES amazônicas. Ao refletir sobre as representações construídas pelo olhar da mídia e da comunicação publicitária, ou seja, as narrativas publicitárias e midiáticas sobre os espaços urbanos das cidades, acreditamos poder contribuir para contar a história da publiCIDADE a partir dos veículos/mídias existentes na região amazônica. Como podemos ler uma cidade a partir das suas relações midiáticas com os espaços urbanos e a comunicação? Ao pensarmos sobre a questão, percebermos que as imagens ou os imaginários podem nos revelar a cidade proposta pela publiCIDADE.

Tomando ainda a publicIDADE de Belém do Pará como exemplo, encontramos na página inicial do site da Belémtur, órgão oficial da Prefeitura de Belém voltado para o turismo, a seguinte descrição:

Portas de entrada do fascinante mundo amazônico. Está localizado na foz direita do rio Amazonas e abaixo $1^{\circ}$ da linha do Equador, por esta razão seu clima é quente e úmido, porém chuvosa e ventilada, o que ameniza o calor de Belém. (BELÉMTUR, 2021)

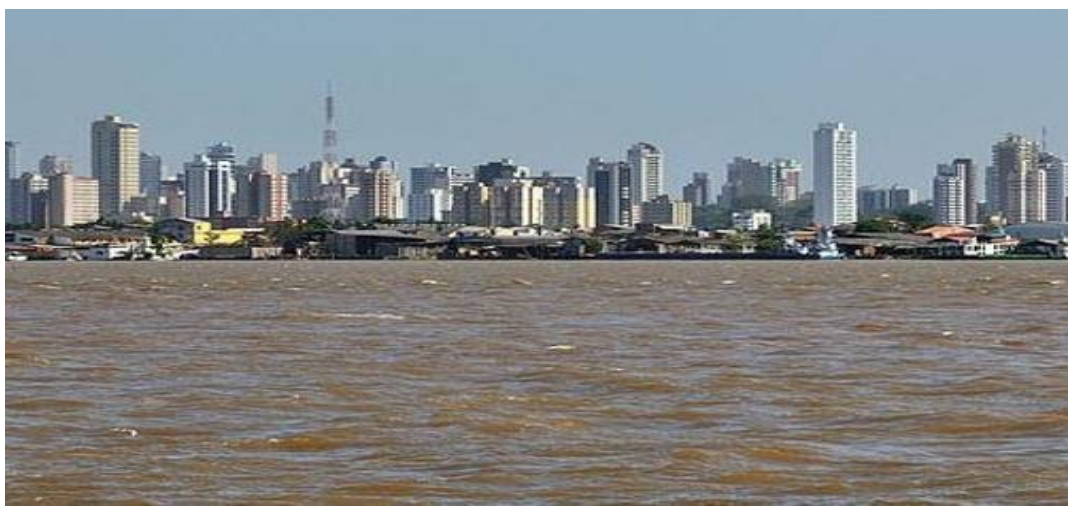

Figura 1. Vista de Belém a partir da baia de Guajará Fonte: Portal Amazônia.

1. O dicionário apresenta-se como uma ferramenta voltada àqueles que querem saber mais sobre desenvolvimento e cidadania global. Disponível em: https://ddesenvolvimento.com/. Acesso em: 20 dez. 2021. 
Historicamente, as cidades de maior ou menor porte territorial nos apresentam, ao longo dos séculos, diversas narrativas históricas, culturais, sociais e publicitárias sobre as mudanças urbanas pelas quais passaram. É por isso que, ao serem estudadas, nos servem de acontecimentos midiáticos de personagens e das mídias que fizeram e fazem parte do cotidiano da vida nas metrópoles localizadas na Amazônia.

Assim, o olhar amazônico da pesquisa se dará por meio das narrativas publicitárias e midiáticas como forma de compreender as conexões existentes entre as marcas e os espaços das publiCIDADES a partir dos veículos/mídias e imagens/imaginários amazônicos, bem como analisar a Amazônia como um espaço territorial (re)conhecido como uma marca. Sobre a representação da Amazônia como uma marca midiática, nos diz Amaral Filho (2016):

A marca Amazônia está na mídia como um discurso cultural, econômico, ecológico e científico, mas o que nos interessa aqui é defini-la como um elemento do sistema de signos da publicidade, logo, como uma proposição ideológica que envolve nomeações, conceitos e imagens com a finalidade precípua de persuadir e seduzir para a compra da mercadoria. (p. 58-59)

A publiCIDADE de Belém ganhou, com o passar dos anos, nomenclaturas que, na maioria das vezes, eram formas de enaltecer as qualidades e as "maravilhas" de uma cidade localizada na Amazônia: Santa Maria de Belém do Grão-Pará, Paris na América, Metrópole da Amazônia, Cidade das Mangueiras e Feliz Lusitânia. Todos esses nomes servem também como identidades marcárias relacionadas à região e que remetem à marca Amazônia:

A imagem da Amazônia, como uma marca, é constituída a partir de estereótipos genéricos como floresta, rios, bichos, índios que estão no imaginário universal e que se juntam a outros de um imaginário popular representado no imaginário mítico como o Boto, a Boiuna, a Iara. Acrescente-se a estes outros conceitos trazidos pelos viajantes como inferno verde, pulmão do mundo, celeiro do mundo, que amplia e se refina possibilitando à publicidade oferecer para a Amazônia outros conceitos ainda, estes trazidos do conhecimento científico, como um inventário simplificado da ciência, em que se apresentam a biodiversidade, o manejo florestal e o desenvolvimento sustentável, entre tantos outros, oriundos do discurso científico. (AMARAL FILHO, 2016, p. 41-42)

Segundo Batey, "o conceito de marca deve encontrar uma expressão, ou pelo menos estar refletido, na comunicação da marca, no nome, no slogan e nos outros elementos de marketing” (BATEY, 2010, p. 269). Ainda,

O significado principal de uma marca é o resumo das principais associações feitas pelo consumidor e das percepções dominantes sobre ela, uma fotografia instantânea que imediatamente vem à mente ao se ouvir o nome da marca. Simplesmente, é a maneira pela qual o consumidor define certa marca espontaneamente. (BATEY, 2010, p. 210)

Em outra direção reflexiva, Perez (2017), por meio de uma abordagem semiótica, afirma que: "A marca é a convergência semiótica de elementos reticulares resultante de uma negociação constante de significados entre os diversos atores sociais do processo comunicacional, por isso é interacional e movente no tempo" (PEREZ, 2017, p. 15). 
Como mencionado, a antiga cidade de Belém, capital da Província do Pará, localizada na região amazônica e fundada em 1616 com o singelo nome de Santa Maria de Belém do Grão-Pará, recebeu posteriormente, como capital do estado do Pará, as denominações simbólicas de Cidade das Mangueiras (Figura 2) e de Metrópole da Amazônia. Desse modo, este estudo também é uma forma de resgatar as histórias locais e apresentar as narrativas sobre as cidades amazônicas como marcas midiáticas de consumo da publiCIDADE e como espaços de interlocução entre o público e o privado dentro dos espaços urbanos reais e imaginários, construídos pela mídia por meio das narrativas publicitárias sobre a cidade, ou seja, a publicIDADE.

Todas essas possibilidades históricas permitem a sinalização da construção de uma paisagem local com o mundo das mercadorias, marcas, produtos e serviços, e dos espaços públicos, tais como ruas do comércio, lojas, praças, teatros e estabelecimentos diversos, dando visibilidade às informações desses espaços em novos lugares de sociabilidade dos grupos sociais existentes em Belém. (SANTOS, 2018, p. 26)

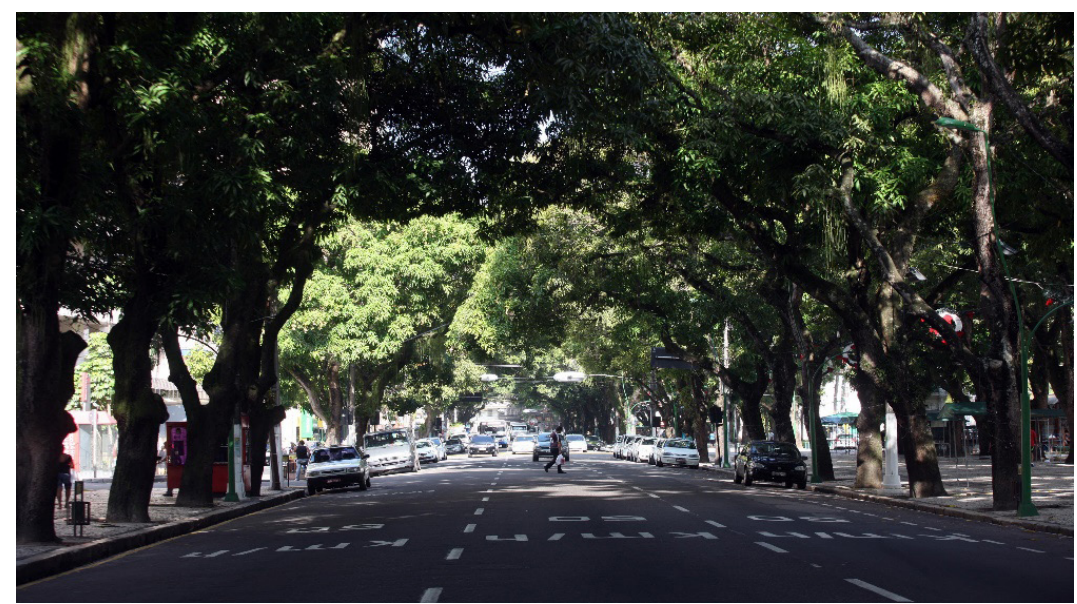

Figura 2. Avenida Presidente Vargas em Belém Fonte: Cláudio Santos | Ag. Pará.

A publicização e midiatização dos espaços urbanos diz respeito tanto a um passado longínquo, com sentido de continuidade, quanto a um presente imediato, relacionado às experiências cotidianas, e a um futuro, que pode ser longínquo ou imediato.

Para que o passado não seja abolido é preciso que tudo o que se vive seja atualizado. As diferenças temporais entre o passado, o presente e o futuro são aniquilados graças aos simulacros dessa atualização. $O$ passado e o futuro parecem se conjugar no presente, ao passo que o próprio presente se torna o tempo da reprodução antecipada do passado. (JEUDY, 2005, p. 16)

Segundo Jeudy (2005, p. 16): “os diferentes momentos vividos ao longo de uma existência representam, como cartões-postais, atmosferas da vida cotidiana que não poderemos jamais esquecer”. Nessa percepção, a partir das narrativas das publicIDADES amazônicas, é requerido do pesquisador uma análise dos fatos históricos e da vida cotidiana retratados nas mídias pesquisadas como forma de descortinar 
o consumo dos e nos espaços urbanos como trilhas midiáticas e, ainda, como espaços publicitários e midiáticos, ou seja, territórios de ocupação da comunicação publicitária e das suas relações midiáticas que vão da aldeia global até a taba urbana e vice-versa.

No caso da publicIDADE, temos os mercados, que representam mais do que um local de compra e venda, de negociação de preço e de quantidade de bens, produtos e serviços entre vendedores e compradores; eles transformam-se num espaço de encontros fundamental para o modo de vida capitalista. E, de modo geral, "concomitantemente com o aparecimento e o desenvolvimento do comércio, surgem também as formas de divulgação, entrando em cena a atividade da publicidade e da propaganda” (SANTOS, 2018, p. 269).

Pensamos que as imagens ou os imaginários podem nos revelar a cidade proposta pela publiCIDADE a partir das nossas reflexões sobre as representações construídas pelos olhares propostos pelas narrativas publicitárias e midiáticas veiculadas e propagadas sobre os espaços urbanos das cidades, dos lugares existentes na região amazônica.

\section{CAMINHANDO PELA PUBLICIDADE EM BELÉM}

Quais os critérios para se ler uma publicIDADE como marca, como mídia, como signo, como expressão do consumo? Ler uma matéria jornalística, um anúncio publicitário ou um livro parece ser menos complicado, porque, ao decodificar a palavra, a imagem do fotojornalismo ou da arte publicitária é, na maioria das vezes, sempre direta. Portanto, nas mais diversas áreas do pensamento humano, as cidades têm sido estudadas como representações de lugares simbólicos e a publiCIDADE pode, então, ser lida - se em texto, imagem ou discurso - e interpretada se expressa na linguagem, textura ou na realidade - de diversas maneiras. O texto, uma vez escrito, adquire a mesma materialidade de um edifício. Estará sempre no lugar em que foi depositado (MALACO, 2017). Ainda: "A materialidade da cidade, tanto para o público como para o privado, é definidora de lugares vazios. Existe a cidade como materialidade, mas o que faz essa matéria, enquanto matéria propriamente social, é definir lugares vazios” (MALACO, 2017, p. 17).

Nesse contexto, a publicIDADE é composta de intensas paisagens de leituras e interpretações a partir dos letreiros, outdoors, cartazes, anúncios, placas de trânsito, sinais, corpos e, ainda, prédios, casas, monumentos, praças, parques, ruas, avenidas, becos, vielas... enfim, de todas as formas verbais e não verbais de ler e ver as coisas que compõem a realidade e o imaginário das publiCIDADES mundo afora.

O leitor, antes de tudo, precisa conhecer a escrita do texto que tenha em suas mãos. Para que um texto possa ser lido, para que possa revelar os conhecimentos que contém, é necessário que o leitor seja capaz de decifrar sua escrita. O texto permanece mudo quando se é incapaz de decifrar seus sinais. Uma cultura não se mantém pela mera preservação de seus textos. (MALACO, 2017, p. 8)

Malaco (2017) também utiliza a ideia de Roland Barthes de que a cidade é como um discurso e "esse discurso é verdadeiramente uma linguagem: a cidade fala a seus habitantes, falamos nossa cidade, a cidade em que nos encontramos, habitando-a simplesmente, percorrendo-a, olhando-a” (MALACO, 2017, p. 40). Portanto, diante dessa percepção da 
cidade como uma escrita que tem algo a dizer, ao vagar pelos espaços públicos - ruas e avenidas, praças e jardins -, o passante ou o morador, ao se deparar com a cidade, tenta decifrar a paisagem urbana por meio de uma leitura desses espaços como a de quem decifra um texto. Para Barros (2007, p. 42), "um texto pode ser definido como algo passível de ser lido, mas também pode ser compreendido como algo que é escrito”.

Os pedestres podem ler o texto urbano, mas eles também o reescrevem, e de algum modo podem ser mesmo considerados como alguns dos personagens ou dos caracteres móveis que fazem parte da construção deste texto urbano. (BARROS, 2007, p. 43)

Portanto, ao lermos uma publicIDADE, podemos perceber suas qualidades, seus defeitos e seus problemas, bem como suas soluções e peculiaridades, como asfalto ou terra, concreto ou mato, prédios ou cabanas, ruas ou rios, avenidas ou florestas, praças ou igarapés etc. O importante é descortinarmos cada detalhe de tudo que ela nos remete, nos conta ou quer nos falar; a publicIDADE é que está sendo pesquisada.

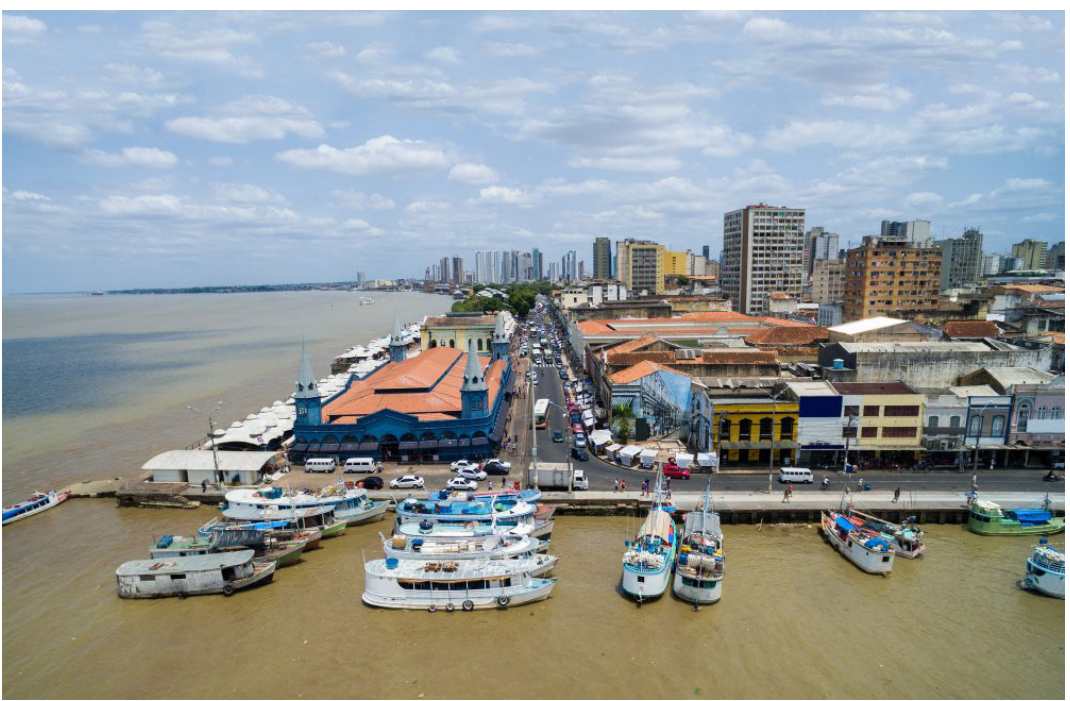

Figura 3. Vista aérea do Ver-o-Peso, em Belém do Pará Fonte: Belémtur (2021).

Para Calvino (1990, p. 18): "o olhar percorre as ruas como se fossem páginas escritas: a cidade diz tudo o que você deve pensar, faz você repetir o discurso [...]". Assim, segundo o autor, "confirma-se a hipótese de que cada pessoa tem em mente uma cidade feita exclusivamente de diferenças, uma cidade sem figuras e sem forma, preenchida pelas cidades particulares” (CALVINO, 1990, p. 34). Na perspectiva de Barros (2007, p. 22), "a cidade deve muito de seu poderoso impacto no imaginário social ao atributo de poder ser contemplada em toda a sua grandeza e totalidade pelo olho humano, desde que tomada a devida distância”.

Ao estudarmos a publicIDADE, outro vocábulo que merece citação é sociedade, do latim societate, um substantivo feminino que, de acordo com Barros (2007), refere-se ao conjunto de pessoas que vivem em certa faixa de tempo e de espaço e que, por conseguinte, seguem normas comuns e "são unidas pelo sentimento de consciência do grupo; corpo social, tais como a sociedade primitiva, medieval, moderna e pósmoderna” (BARROS, 2007, p. 17). A sociedade é, assim, o que nos remete, 
segundo o autor, às diversas sociedades surgidas com o tempo, sejam elas religiosas, esportivas, culturais, científicas, profissionais, políticas, civis, econômicas - por exemplo, as sociedades anônimas (S.A) -, comerciais, de capital e indústria, de economia mista ou, por fim, de consumo.

Para Barros (2007, p. 17), "não podemos deixar de observar que a palavra capital, que vem do latim capitale, é ao mesmo tempo o substantivo feminino referente à cidade que aloja a alta administração de um país ou de um estado, província, departamento etc.”. Ainda que a palavra, como substantivo masculino, refira-se à "riqueza ou valores disponíveis e como um conjunto de bens produzidos pelo homem”, historicamente é marcante a relação do termo cidade com alguns conceitos da economia.

$\mathrm{O}$ universo da economia e das mercadorias e suas mensagens publicitárias também nos reporta aos hábitos, sociabilidades e modos de vida dos habitantes da publiCIDADE. Na sua função normatizadora de propor uma cultura do consumo, a publiCIDADE põe em destaque os valores e comportamentos que deseja disseminar entre os citadinos. Ademais, a publicIDADE busca divulgar o seu texto em meios jornalísticos e publicitários e, por isso, publica na página inicial do site da Belémtur sobre a "Capital do Norte":

Exerce significativa influência nacional, seja do ponto de vista cultural, gastronômico, econômico ou político. Conta com importantes monumentos, parques e museus, como o Theatro da Paz, o Museu Paraense Emílio Goeldi, o Mercado do Ver-o-Peso, e eventos de grande repercussão, como o Círio de Nazaré. (BELÉMTUR, 2021)

Conforme o momento histórico dos estudos sobre sua formação, a cidade, de um modo geral, agrega diversas nomenclaturas, a saber: "artefato e ambiente, sistema e ecossistema, máquina e empresa, monumento e obra de arte, e até mesmo texto como forma de ler os códigos de uma sociedade" (BARROS, 2007, p. 20). Ainda segundo Barros, basta lembrarmo-nos das inúmeras metáforas sobre a cidade, tais como:

Centro e periferia, campo e cidade, ímã e redes, tecido e coração (aqui a cidade vista como um organismo biológico), uma grande família e, finalmente, modernamente a cidade vista como um sistema e seus inúmeros subsistemas, consistindo nisto a riqueza da vida urbana. (BARROS, 2007, p. 20)

Dentro do fator historicidade, faz-se necessário reafirmar o fato de que as formas urbanas, ou seja, as cidades, como mostramos, são produtos da História. Por este motivo, as cidades, nos mais diferentes períodos, parecem apresentar os mesmos problemas comuns ou aparentemente próximos, ou seja, os problemas resultantes de fatores demográficos, econômicos, políticos, sociais, culturais etc.

\section{CONSIDERAÇÕES FINAIS}

Para ler a cidade, outra grafia que também pensamos ao escrever público+cidade é "publi". A cidade demonstra qual é o ponto de interseção entre o que é público dentro da cidade e o que é citadino em relação ao que é público. 
Se a cidade é um texto que pode ser lido a partir da materialidade urbana, e se é possível imaginar os pedestres do passado que percorriam este texto em pontilhado - ou seja, realizavam percursos -, é preciso lembrar que o ato de caminhar através de uma cidade é uma operação complexa que envolve muitos outros gestos e sentidos para além do movimento das pernas e do deslocamento no espaço. (BARROS, 2007, p. 44)

Contudo, decidimos conceitualmente pela grafia do termo publiCIDADE com "publi" em caixa baixa e "CIDADE” em caixa alta -, pois tal forma demonstra a importância da cidade na sua relação direta com o que é público e faz referência ao que é público na relação cotidiana com a cidade.

A cidade também fala aos seus habitantes e aos seus visitantes através dos nomes próprios que ela abriga: dos nomes de ruas, de edifícios, de monumentos. O grande texto urbano aloja dentro de si textos menos, feitos de placas de ruas que evocam memórias e imaginários, de cartazes que são expostos nas avenidas para seduzir e informar, de sinais de trânsito que marcam o ritmo da alternância entre a passagem permitida e os interditos aos deslocamentos no espaço. A cidade é um grande texto que tece dentro de si uma miríade de outros textos, inclusive os das pequenas conversas produzidas nos encontros cotidianos. (BARROS, 2007, p. 46)

Portanto, seja qual for a nomenclatura utilizada para se referir a público+cidade - publi, cidade ou publicIDADE -, o importante é o estudo, a pesquisa que será feita sobre os diversos lugares, espaços, recantos da imensidão desse vasto mundo amazônico. Sendo assim, ao pensarmos nas diversas nomenclaturas e metáforas sobre a(s) cidade(s), por que não inserir a(s) publiCIDADE(S) nesses percursos exploratórios de pesquisa? Se é válido dizer que a cidade pode ser lida e decifrada como um texto ou uma imagem, por que não ler a cidade por meio dos reclames e anúncios publicitários produzidos e divulgados nos meios de comunicação e nos muros da(s) publicIDADE(S)?

Mas é também a cidade a sede de uma cultura material específica. Sinais, placas de trânsito, bancas de jornal, postes, viadutos, arranha-céus - são estes os artefatos da cidade moderna, da mesma forma que a cidade antiga ou a cidade medieval teriam os seus próprios artefatos urbanos, tornando-se também a sede de uma cultura material singular. (BARROS, 2007, p. 83)

Em outras palavras, a grande maioria das cidades apresentam questões relacionadas à produção, à distribuição e ao consumo de bens e serviços, fatores que são adquiridos na passagem de um século para outro. Ainda, tais fatores são um dos grandes objetos de análise das ciências sociais em relação às atividades industriais, comerciais e de consumo nas sociedades pós-industriais das metrópoles modernas, lugares que também podemos denominar de publicIDADES modernas.

Ao refletirmos sobre as relações comunicacionais entre a publicidade, a propaganda e o viver urbano na(s) publiCIDADE(S), analisando todas as representações construídas pelo olhar da comunicação, chegamos à conclusão de que a(s) publiCIDADE(S) são focos riquíssimos de possibilidades de estudo da(s) sociedade(s) que a(s) produz(em) e da(s) sociedade(s) e do(s) público(s) que a(s) consome(m). Para este estudo 
utilizamos, de forma bem simples, alguns aspectos da publiCIDADE de Belém do Pará como forma de propor que a publicidade deve ser estudada como uma narrativa capaz de revelar e desvelar, conforme afirma Rocha (2006, p. 78): “[...] valores que indicam práticas sociais, fomentam significados que atribuímos às nossas vidas, orientam formas pelas quais nos relacionamos com as coisas e com as outras pessoas”. Portanto, como explicitado, o mesmo raciocínio pode ser aplicado ao conceito de publicIDADE proposto por este artigo.

\section{REFERÊNCIAS}

AMARAL FILHO, Otacílio. Marca Amazônia: o marketing da floresta. Curitiba: CRV, 2016.

BARBOSA, Lívia; CAMPBELL, Colin. Cultura, consumo e identidade. Rio de Janeiro: Editora FGV, 2006.

BARROS, José D’Assunção. Cidade e história. Petrópolis: Vozes, 2007.

BATEY, Mark. O significado da marca: como as marcas ganham vida na mente dos consumidores. Rio de Janeiro: Best Business, 2010.

BELÉMTUR. Belémtur: tudo aqui é vida, 2021. Disponível em: https://belemtur.belem. pa.gov.br/. Acesso em: 20 dez. 2021.

BELÉMTUR. Inventário da oferta turística de Belém. Belém: Prefeitura de Belém, 2019.

CALVINO, Italo. As cidades invisíveis. São Paulo: Companhia das Letras, 1999.

CANEVACCI, Massimo. A cidade polifônica: ensaio sobre a antropologia da comunicação urbana. São Paulo: Studio Nobel, 1993.

CIDADES. Dicionário do desenvo/vimento, 2020. Disponível em: https://ddesenvolvimento. com/portfolio/cidades/. Acesso em: 20 dez. 2021.

HABERMAS, Jurgen. Mudança estrutural da esfera pública: investigações quanto a uma categoria da sociedade burguesa. 2. ed. Rio de Janeiro: Tempo Brasileiro, 2003.

LE GOFF, Jacques. Por amor às cidades: conversações com Jean Lebrun. São Paulo: Fundação Editora Unesp, 1998.

LEFEBVRE, Henri. O direito à cidade. São Paulo: Moraes, 1991.

LYNCH, Kevin. A imagem da cidade. 3. ed. São Paulo: Martins Fontes, 2011.

MALACO, Jonas Tadeu Silva. Cidade: ensaio de aproximação conceitual. Viana do Castelo: Alice Foz, 2017.

MUMFORD, Lewis. A cidade na história: suas origens, transformações e perspectivas. São Paulo: Martins Fontes, 1965.

PEREZ, Clotilde. Signos da marca: expressividade e sensorialidade. 2. ed. São Paulo: Cengage Learning, 2017.

ROCHA, Everardo. Representações do consumo: estudo sobre a narrativa publicitária. Rio de Janeiro: Editora PUC-Rio; Mauad, 2006.

SANTOS, Douglas. A reinvenção do espaço. São Paulo: Editora Unesp, 2002.

SANTOS, Luiz LZ Cezar Silva dos. PubliCIDADE na Belém da belle époque entre os anos de 1870 e 1912. Curitiba: Appris, 2018. 